LACERDA TANURE, Augusto; CAMPOS GALUPPO, Marcelo. O embondeiro e a tolerância. Revista Eletrônica Direito e Política, Programa de Pós-Graduação Stricto Sensu em Ciência Jurídica da UNIVALI, Itajaí, v.16, n.1, $1^{0}$ quadrimestre de 2021. Disponível em: www.univali.br/direitoepolitica - ISSN 1980-7791.

\title{
O EMBONDEIRO E A TOLERÂNCIA
}

\author{
THE BAOBAB AND TOLERATION
}

\section{Augusto Lacerda Tanure ${ }^{1}$ Marcelo Campos Galuppo²}

\section{RESUMO}

O presente artigo têm como objetivo discutir a tolerância e seus limites no tocante à liberdade de expressão. Questionará a possibilidade ou impossibilidade de definir quais discursos deveriam disputar o mercado de ideias democrático. Para tanto, tecerá reflexões a partir do texto: "O embondeiro que sonhava pássaros" de Mia Couto, contrapondo-o às ideias sobre tolerância de Jeremy Waldron em "The Harm in Hate Speech" e Andrew Jason Cohen em "Toleration and Freedom From Harm". Pretende-se demonstrar que a liberdade de expressão é essencial à tolerância, sendo que suas limitações devem ser as mínimas possíveis.

PALAVRAS-CHAVE: tolerância; liberdade de expressão; identidade; violência

\begin{abstract}
This article aims to discuss tolerance and its limits with regard to freedom of expression. It will question the possibility or impossibility of defining which speeches should compete for the democratic ideas market. To this end, it will uses "O embondeiro que sonhava pássaros" by Mia Couto, contrasting it with the ideas about toleration by Jeremy Waldron in "The Harm in Hate Speech" and Andrew Jason Cohen in "Toleration and Freedom From Harm". It is intended to demonstrate that freedom of expression is essential to toleration, and its limitations should be kept to a minimum.
\end{abstract}

KEY-WORDS: toleration; freedom of expression; identity; violence

\footnotetext{
1 Mestrando em Direito, na linha Teoria do Direito e da Justiça, pela Faculdade Mineira de Direito (PUC Minas). Belo Horizonte, Minas Gerais, Brasil. CV Lattes: http://lattes.cnpq.br/8812298341348018. Bolsista CAPES. Advogado. E-mail: altanure@gmail.com. 2 Doutor em Filosofia do Direito pela UFMG. Professor da Faculdade Mineira de Direito da Pontifícia Universidade Católica de Minas Gerais (PUC Minas). Professor da Faculdade de Direito da Universidade Federal de Minas Gerais (UFMG) Belo Horizonte (MG), Brasil. ORCID: https://orcid.org/0000-0003-2329-6695. CV Lattes: http://lattes.cnpq.br/3883590920517833. Email: marcelogaluppo@uol.com.br.
} 
LACERDA TANURE, Augusto; CAMPOS GALUPPO, Marcelo. O embondeiro e a tolerância. Revista Eletrônica Direito e Política, Programa de Pós-Graduação Stricto Sensu em Ciência Jurídica da UNIVALI, Itajaí, v.16, n.1, $1^{0}$ quadrimestre de 2021. Disponível em: www.univali.br/direitoepolitica - ISSN 1980-7791.

\section{INTRODUÇÃo}

É um problema sermos intolerantes "com as causas diferentes do comum"? ${ }^{3} \mathrm{O}$ tolerante deveria "gastar saliva com quem não vale um cuspe"? ${ }^{4}$. Estamos sendo "excessivamente tolerantes" e "a livre circulação de ideias intolerantes (...), fatalmente, leva também, em algum momento, a atos violentos"? ${ }^{6}$

Deveríamos ser mais atentos a ideia de tolerância que cultivamos na sociedade. Ser intolerante, especialmente com ideias, pode ser cruel, afinal, definir o que deve ser tolerado e o limite do tolerar é definir o que mesmo não gostando, devemos aceitar e discutir na sociedade. Mas, o que se pode expressar? É possível determinar quais discursos deveriam disputar o mercado de ideias democrático e quais não deveriam? Quem é o outro que pode ter voz? Certamente não o "O embondeiro que sonhava pássaros" no conto de Mia Couto7.

\section{O EMBONDEIRO QUE SONHAVA PÁSSAROS}

A história do escritor moçambicano Mia Couto começa apresentando um homem condenado à sombra, sem identidade, que habitava como se fosse um estranho. Contrastando com o fato de ser sombra, todos os dias o passarinheiro, negro, passeava pelos bairros dos brancos, carregando suas gaiolas e, nelas, os pássaros mais belos.

\footnotetext{
3 MICELI Maria Zélia Dias. A intolerância no brasil e no mundo. Estadão, São Paulo. Disponível em: https://educacao.estadao.com.br/blogs/blog-dos-colegios-santa-amalia/a-intolerancia-no-brasil-eno-mundo/ Acesso em 15/11/2019.

${ }^{4}$ BETTO, Frei. Arte da Tolerância. Disponível em: https://www.freibetto.org/index.php/artigos/14artigos/18-arte-da-tolerancia. Acesso em: 15/11/2019

5 BRAGA, Giampaolo Morgado. Em segurança pública, nosso problema é excesso de tolerância. Revista Época, Rio de Janeiro. Disponível em: <https://epoca.globo.com/em-seguranca-publicanosso-problema-excesso-de-tolerancia-23634880 >. Acesso em: 15/11/2019

${ }^{6}$ BUGALHO, Henry. Eles não podem vencer: a intolerância não pode sufocar a voz dos tolerantes. Carta Capital, Rio de Janeiro. Disponível em: https://www.cartacapital.com.br/opiniao/eles-naopodem-vencer-a-intolerancia-nao-pode-sufocar-a-voz-dos-tolerantes/. Acesso em: 15/11/2019

7 COUTO, Mia.O Embondeiro que sonhava pássaros. In: .Cada homem é uma raça. São Paulo: Companhia das Letras, 2013.
} 
LACERDA TANURE, Augusto; CAMPOS GALUPPO, Marcelo. O embondeiro e a tolerância. Revista Eletrônica Direito e Política, Programa de Pós-Graduação Stricto Sensu em Ciência Jurídica da UNIVALI, Itajaí, v.16, n.1, $1^{0}$ quadrimestre de 2021. Disponível em: www.univali.br/direitoepolitica - ISSN 1980-7791.

As crianças se encantavam com os pássaros, as cores e as melodias que o passarinheiro harmonicava. Os adultos, atrás de suas janelas, enchiam-se de suspeitas e preconceitos. Queriam saber quem autorizara o negro a desvirtuar o bairro e sua rotina; sua calmaria; seu padrão. Afinal, "aquele preto quem era? Alguém conhecia recomendações dele? Quem autorizara aqueles pés descalços a sujarem o bairro? Não, não e não. O negro que voltasse ao seu devido lugar"8. E os pais restringiam os meninos de se encontrarem com o passarinheiro.

O início da história escancara a dificuldade de lidar com o diferente - o sem identidade - materializado na figura do passarinheiro. Ao mesmo tempo, enfatiza o contraste entre o acolhimento das crianças e a desconfiança dos adultos. Um ponto merece destaque, enquanto a acolhida acontece na rua, a desconfiança se inicia por trás das janelas. Será que na nossa sociedade não repetimos o mesmo padrão? As desconfianças e preconceitos não começam por trás das cortinas?

As restrições dos pais, no entanto, não eram muito eficazes, especialmente na casa de Tiago. Ao avistar o passarinheiro chegando, o menino corria ao seu encontro, para a tristeza de seu pai. Um dia, após as reprimendas, o pai se reuniu, no clube, com os demais colonos para maldizer o passarinheiro. Queriam transformá-lo em sombra, ainda que não fosse a medida "morte matada, nem coisa que ofendesse a vista das senhoras e seus filhos". ${ }^{9}$

As restrições não funcionavam. A censura pouco adiantava. Mas, novamente, o espaço das confabulações é um espaço fechado. O clube é onde maldizia-se o passarinheiro, onde procurava-se justificativa e respaldo para punir o homem que deturpava a ordem. Mas se não há justificativa forte, não se deve punir, até, pelo menos, se encontrar uma.

Os colonos adultos, então, hesitaram tomar as "devidas" medidas contra o passarinheiro, mas não puderam se segurar quando perceberam as mudanças trazidas pelas visitas do passarinheiro. O som do bairro se alterou com o mundo de pássaros - inalcançável pelos colonos adultos - trazidos pelo passarinheiro e

\footnotetext{
8 COUTO, Mia.O Embondeiro que sonhava pássaros. p. 64;

9 COUTO, Mia.O Embondeiro que sonhava pássaros. p. 65;
} 
LACERDA TANURE, Augusto; CAMPOS GALUPPO, Marcelo. O embondeiro e a tolerância. Revista Eletrônica Direito e Política, Programa de Pós-Graduação Stricto Sensu em Ciência Jurídica da UNIVALI, Itajaí, v.16, n.1, $1^{0}$ quadrimestre de 2021. Disponível em: www.univali.br/direitoepolitica - ISSN 1980-7791.

comprados pelos colonos. As crianças passaram a frequentar mais a rua do que suas casas e começavam a imaginar o passarinheiro, negro, como parente. As janelas das casas se abriam, as gavetas apareciam trocadas, os móveis revirados, contrariando a ordem desejada pelos adultos ${ }^{10}$. A casa, comandada pelos pais, estava "ameaçada" pelo passarinheiro.

Sem justificativa, hesita-se punir. Mas ao encontrá-la, pode-se agir, ainda que este agir se baseie somente no incomodo provocado na sociedade. Imagino os colonos pensando "como pode um passarinheiro negro causar esse alvoroço e, agora, no meu lugar de ordem?" As medidas passam a serem justificadas. Mas, essas decisões - as de justificativa duvidosa - devem ser tomadas em lugar fechado, no caso, na casa do pai de Tiago. Não se deve discutir publicamente o injustificável.

Assim, os colonos se reuniram na casa de Tiago e marcharam em direção ao embondeiro, cujo tronco servia de morada ao passarinheiro. Antecipando-os, Tiago já havia saído de casa para avisar o passarinheiro, agora, mais do que nunca, pessoa de grande valor para o menino. Ao avisá-lo, o passarinheiro colocou a melhor roupa e, contrariando a expectativa do menino, esperou para receber as visitas. ${ }^{11}$

Os colonos chegaram. Tiago se escondeu. O passarinheiro foi agredido e preso no calabouço para ser torturado. Nem os colonos, nem o algoz sabiam o motivo e as informações que queriam extrair do passarinheiro. Bastavam as pancadas e uma justificativa genérica, para não parecer violência gratuita. Tiago, do lado de fora, pega a gaita do passarinheiro, atirada pelo torturador, e adormece tocando-a, na tentativa de consolar o passarinheiro.

Ao acordar, o menino não o encontrou, razão pela qual foi até o embondeiro a sua procura. Ele não estava lá, mesmo assim, Tiago entrou no tronco da árvore e começou a tocar a gaita. Os colonos ouviram e logo creditaram a música ao passarinheiro, o qual parecia não ter aprendido a lição. ${ }^{12}$ Tacaram fogo no

${ }^{10}$ COUTO, Mia.O Embondeiro que sonhava pássaros. p. 65-67;

${ }^{11}$ COUTO, Mia.O Embondeiro que sonhava pássaros. p. 68;

12 COUTO, Mia.O Embondeiro que sonhava pássaros. p. 69-71; 
LACERDA TANURE, Augusto; CAMPOS GALUPPO, Marcelo. O embondeiro e a tolerância. Revista Eletrônica Direito e Política, Programa de Pós-Graduação Stricto Sensu em Ciência Jurídica da UNIVALI, Itajaí, v.16, n.1, $1^{0}$ quadrimestre de 2021. Disponível em: www.univali.br/direitoepolitica - ISSN 1980-7791.

embondeiro por vingança, e então, não há como contar a história se não pelas palavras de Mia Couto:

As tochas se chegaram ao tronco, o fogo namorou as velhas cascas. Dentro, o menino desatara um sonho: seus cabelos se figuravam pequenitas folhas, pernas e braços se madeiravam. Os dedos, lenhosos, minhocavam a terra. O menino transitava do reino: arvorejado, em estado de consentida impossibilidade. E do sonâmbulo embondeiro subiam as mãos do passarinheiro. Tocavam as flores, as corolas se envolucravam: nasciam espantosos pássaros e soltavam-se petalados, sobre a crista das chamas. As chamas? De onde chegavam elas, excedendo a lonjura do sonho? Foi quando Tiago sentiu a ferida das labaredas, a sedução da cinza. Então, o menino, aprendiz da seiva, se emigrou inteiro para suas recentes raízes. ${ }^{13}$

A riqueza do conto é impressionante, razão pela qual, necessário que seja melhor analisado em tópico apartado. Não há a pretensão, no entanto, de o exaurir, afinal, como exaurir a literatura? Mas a análise servirá para enriquecer as discussões tão atuais sobre a tolerância, trazendo novas reflexões e questionamentos.

Para tanto, no próximo tópico, o conto será analisado sob o foco da tolerância. Após, deseja-se contrapor as reflexões trazidas pelo livro às ideias de tolerância de Jeremy Waldron e Andrew Jason Cohen, construídas em seus livros "The Harm in Hate Speech"14 e "Toleration and Freedom From Harm"15, respectivamente. Ao fim, pretende-se contribuir para o debate sobre a tolerância, apresentando alguns pontos que merecem consideração.

\section{A RIQUEZA DO EMBONDEIRO QUE SONHAVA PÁSSAROS}

O conto de Mia Couto gera reflexões sobre o direito e a sociedade como um todo. Neste tópico, porém, pretende-se explorar àquelas relativas à tolerância e a liberdade de expressão. O nosso problema, afinal, é sobre a tolerância no discurso e, portanto, sobre o que se deve poder expressar.

\footnotetext{
13 COUTO, Mia.O Embondeiro que sonhava pássaros. p. 71;

14 WALDRON, Jeremy. The Harm in Hate Speech. Cambridge: HarvardUniversity Press, 2012.

15 COHEN, Andrew Jason. Toleration And Freedom From Harm: liberalism reconceived. New York: Routledge, 2018.
} 
LACERDA TANURE, Augusto; CAMPOS GALUPPO, Marcelo. O embondeiro e a tolerância. Revista Eletrônica Direito e Política, Programa de Pós-Graduação Stricto Sensu em Ciência Jurídica da UNIVALI, Itajaí, v.16, n.1, $1^{0}$ quadrimestre de 2021. Disponível em: www.univali.br/direitoepolitica - ISSN 1980-7791.

Não será foco a abordagem mais comumente realizada sobre os aspectos coloniais e identitários de raça, apesar de, sem sombra de dúvidas, serem o destaque dado pela maioria dos autores à literatura de Mia Couto ${ }^{16}$. Tais questões serão trabalhadas de forma indireta, perpassando a temática da tolerância e da liberdade de expressão.

Por este motivo, necessário uma compreensão, pelo menos provisória, de tolerância. Em uma definição menos rigorosa, é a "tendência a admitir, nos outros, maneiras de pensar, de agir e de sentir diferentes ou mesmo diametralmente opostas às adotadas por si mesmo". ${ }^{17}$ Assim, ainda que se pense a tolerância de uma forma simplificada, dois pontos são essenciais: diferença de opiniões, crenças (e algumas vezes de características - como a cor da pele) e aceitação/tendência de admitir o diferente.

A diferença entre o passarinheiro e os colonos adultos é a todo momento, enfatizada por estes. O desprezo pelo passarinheiro se transfigura no desprezo por sua música, assim como na comparação que os colonos fazem entre o vendedor e os bichos. ${ }^{18}$ Mas será que existe aceitação? Alguns poderiam dizer que sim, já que, pelo menos até o momento em que o perseguem, ele era "tolerado" nas ruas da cidade. Outros diriam que não, afinal, mesmo antes, ele não era acolhido: existiam desprezo, preconceito e maldizeres.

\footnotetext{
${ }^{16}$ Com esse enfoque, vários trabalhos de qualidade despontam, tais como BEZERRA, Rosilda Alves; TEIXEIRA, João Batista. Relações identitárias e infância no conto de mia couto: o embondeiro que sonhava pássaros.In. V Colóquio Internacional Cidadania Cultural: Jovens nos espaços públicos e institutucionais da modernidade, 2011.; CHASSOT, Jaqueline. A lógica simbólica e a representação da personagem em "o embondeiro que sonhava pássaros", de mia couto. Revista InterteXto, $\quad v . \quad 3, \quad n . \quad 2, \quad$ jan. 2011. Disponível em: <http://seer.uftm.edu.br/revistaeletronica/index.php/intertexto/article/view/108>. Acesso em: 11 jan. 2020 e MICHELETTI, Everton Fernando. O "terceiro espaço" em "O embondeiro que sonhava pássaros", de Mia Couto, e "A árvore que tinha batucada", de Boaventura Cardoso. XIII Congresso Internacional da ABRALIC Internacionalização do Regional. Campina Grande: Editora Realize. 2013. Disponível em: <https://www.editorarealize.com.br/revistas/abralicinternacional/trabalhos/Completo_Comunicaca o_oral_idinscrito_687_03bc553d89a018eae05335d7074beaa8.pdf>. Acesso em: 11/01/2020.

${ }^{17}$ HOUAISS, Antônio. Houaiss Eletrônico. Rio de. Janeiro, Ed. Objetiva, 2009

${ }^{18}$ CHASSOT, Jaqueline. A lógica simbólica e a representação da personagem em "o embondeiro que sonhava pássaros", de mia couto. p. 27-28.
} 
LACERDA TANURE, Augusto; CAMPOS GALUPPO, Marcelo. O embondeiro e a tolerância. Revista Eletrônica Direito e Política, Programa de Pós-Graduação Stricto Sensu em Ciência Jurídica da UNIVALI, Itajaí, v.16, n.1, $1^{0}$ quadrimestre de 2021. Disponível em: www.univali.br/direitoepolitica - ISSN 1980-7791.

Apesar do possível impasse, a violência, por certo, põe um fim em qualquer possibilidade de tolerância. Elimina-se o que é perturbador; o que causa medo, ${ }^{19}$ o que é contrário. Frente às diferenças culturais e raciais, os colonos tentam dominar e quando se ameaça a ordem e a dominação, recorrem a violência. ${ }^{20} \mathrm{Fica}$ a dúvida sobre quão exigente se pode ser com a sociedade com o ato de tolerar.

Mas desconsideremos por um momento essa dificuldade. Como a diferença levou à violência, no conto? Micheletti ${ }^{21}$ enfatiza que a língua e o discurso de superioridade do colonizador são capazes de acentuar e marcar as diferenças. Uma diferença cada vez mais delimitada poderia, segundo o autor, gerar uma polarização entre o colonizador e o colonizado. Acredito que para além desse fator há outro que se encontra nas entrelinhas. Em momento algum há um diálogo equânime.

O conto é um retrato de um passarinheiro negro silenciado. Ele, aos poucos se insere, na comunidade local, ainda que os colonos adultos brancos não o recebam com acolhimento. No entanto, quando ele começa a alterar a rotina e os costumes locais; quando os pássaros começam a fazer barulho; quando as crianças começam a preferir as ruas às casas; quando sua lógica mágica e mítica atrapalha a ordem lógico-racional estabelecida 22 , nesse momento a violência o cala. Como observa Micheletti:

O velho é levado à prisão, o menino segue sem ser visto, ouve e observa do lado de fora. A violência decorre da intolerância pelo outro, da busca por manter a dominação sobre os colonizados, pois o outro e sua cultura ameaçam ao alterar a ordem da organização social colonial: o negro no bairro dos brancos, as crianças próximas dele, os encantos causados pelos pássaros. Por isso, quando os

\footnotetext{
${ }^{19}$ CHASSOT, Jaqueline. A lógica simbólica e a representação da personagem em "o embondeiro que sonhava pássaros", de mia couto. p. 29.

20 MICHELETTI, Everton Fernando. O "terceiro espaço" em "O embondeiro que sonhava pássaros", de Mia Couto, e "A árvore que tinha batucada", de Boaventura Cardoso. p. 1-3.

${ }^{21}$ MICHELETTI, Everton Fernando. O "terceiro espaço" em "O embondeiro que sonhava pássaros", de Mia Couto, e "A árvore que tinha batucada", de Boaventura Cardoso. p. 2.

22 Para um breve, mas interessante debate sobre a dualidade mítico e lógico-racional presente no conto, ler CHASSOT, Jaqueline. A lógica simbólica e a representação da personagem em "o embondeiro que sonhava pássaros", de mia couto. p. 30-31.
} 
LACERDA TANURE, Augusto; CAMPOS GALUPPO, Marcelo. O embondeiro e a tolerância. Revista Eletrônica Direito e Política, Programa de Pós-Graduação Stricto Sensu em Ciência Jurídica da UNIVALI, Itajaí, v.16, n.1, $1^{0}$ quadrimestre de 2021. Disponível em: www.univali.br/direitoepolitica - ISSN 1980-7791.

colonos mandam interrogar, o guarda nem "sabia que segredos devia arrancar do velho". ${ }^{23}$

O silenciamento é um processo. Primeiro os colonos adultos o descreditam frente as crianças, depois o comparam a bichos selvagens e, após, proíbem as crianças de se encontrarem com ele - a única parte daquela sociedade disposta a estar com o passarinheiro. Um detalhe, porém, pode passar despercebido ao leitor um pouco desatento: grande parte deste silenciamento se encontra nas decisões tomadas pelos homens adultos em espaços de acesso restritos. Os adultos se enchem de suspeitas por trás de suas janelas. ${ }^{24} \mathrm{O}$ pai de Tiago maldiz o passarinheiro no clube. ${ }^{25} \mathrm{~A}$ decisão de punir o passarinheiro se forma na casa do pai de Tiago. ${ }^{26} \mathrm{Em}$ nenhum desses lugares há acesso do passarinheiro nem de ninguém que o represente ou apresente seu discurso.

Aliás, o ferem na boca. Se a música (dele e dos pássaros) foi o meio que o fez inserir-se provisoriamente naquela comunidade, é na boca que o acertam. Não mais poderia se expressar. Como lembrado por Micheletti, 27 em outras circunstâncias, "as relações culturais poderiam ocorrer de outra forma, sem intolerância, sem a violência que acabou impedindo-o de tocar".

Nesse mundo de silêncios e silenciadores, Tiago foi quem ouviu a música do passarinheiro e tocou a sua própria posteriormente. Tiago mostra alteridade e capacidade de querer um mundo melhor, um mundo de músicas e encantos; o diferente trazido pelo passarinheiro. Tiago desafia esse mundo totalitário desenhado pelos colonos adultos:

\footnotetext{
Assim, as situações de violência presentes no conto 0 embondeiro que sonhava pássaros evidenciam esse quadro de totalitarismos e sistemas que não se permitem um discurso por um mundo melhor, uma heteronomia como idealização de dias melhores para os povos. (...) Nessa visão, compreender o modo como o menino Tiago se mistura ao mundo do passarinheiro, já nos coloca frente a um novo discurso, o de que tais regimes totalitários estão sendo postos em

23 MICHELETTI, Everton Fernando. O "terceiro espaço" em "O embondeiro que sonhava pássaros", de Mia Couto, e "A árvore que tinha batucada", de Boaventura Cardoso. p. 6.

${ }^{24}$ COUTO, Mia.O Embondeiro que sonhava pássaros. p. 64.

${ }^{25}$ COUTO, Mia.O Embondeiro que sonhava pássaros. p. 65.

${ }^{26}$ COUTO, Mia.O Embondeiro que sonhava pássaros. p. 68.

27 MICHELETTI, Everton Fernando. O "terceiro espaço" em "O embondeiro que sonhava pássaros", de Mia Couto, e "A árvore que tinha batucada", de Boaventura Cardoso. p. 6.
} 
LACERDA TANURE, Augusto; CAMPOS GALUPPO, Marcelo. O embondeiro e a tolerância. Revista Eletrônica Direito e Política, Programa de Pós-Graduação Stricto Sensu em Ciência Jurídica da UNIVALI, Itajaí, v.16, n.1, $1^{0}$ quadrimestre de 2021. Disponível em: www.univali.br/direitoepolitica - ISSN 1980-7791.

xeque, à medida que se propõe um diálogo com o diferente, e ao mesmo tempo nos sentindo a parte que faz esse todo. ${ }^{28}$

Tiago propõe diálogo com o diferente. É o diálogo que permite a existência da troca entre ele e o passarinheiro. No monólogo restrito e realizado a portas fechadas dos colonos adultos é impossível de se chegar a outra posição que não a violência unilateral com o diferente. Os preconceitos se formaram e não há qualquer possibilidade de serem confrontados. Observe, deslocar os maldizeres do lugar fechado para a rua não traz certeza de que a violência não ocorrerá. Mas, enquanto, ditos à portas cerradas; enquanto filhos de um único ponto de vista, não há possibilidade de não violência. A liberdade de expressão e o diálogo não são a solução de todos os problemas, mas representam a possibilidade de mudança dos acontecimentos.

Quando não há liberdade de expressão, o receber o outro está sempre maculado pelo não-recebimento que esconde. No caso do conto, ainda que se considerasse que havia aceitação (e tolerância) antes dos episódios de violência, a aparente tolerância foi construída na ausência de diálogo e, assim, escondia o silencio; o ódio latente, não passando de calmaria antes da tempestade. Era potência de violência.

A violência é o agir do não dialogo e, no conto - assim como na sociedade esconde um fim trágico. A raiva e violência dos colonos mata Tiago, como também matamos Tiagos. A tragédia é anunciada no começo do conto quando o menino explica que o embondeiro é capaz de grandes tristezas e por isso se suicida ${ }^{29}$, reforçada quando se diz que o embondeiro é capaz de vingar-se daqueles que o fazem $\mathrm{mal}^{30}$ - o que depois é confirmado quando o pai de Tiago provoca a morte de seu filho. A tragédia é confirmada quando o passarinheiro nasce sombra e continua sombra ${ }^{31}$, sem qualquer direito de fala, silenciado na ausência de diálogo entre colonos adultos e passarinheiro. Não dizer mata tudo aquilo que ultrapassa

\footnotetext{
28 TEIXEIRA, João Batista. Relações identitárias e infância no conto de mia couto: o embondeiro que sonhava pássaros. p. 3.

${ }^{29}$ COUTO, Mia.O Embondeiro que sonhava pássaros. p. 64-65.

30 COUTO, Mia.O Embondeiro que sonhava pássaros. p. 68.

31 COUTO, Mia.O Embondeiro que sonhava pássaros. p. 63.
} 
LACERDA TANURE, Augusto; CAMPOS GALUPPO, Marcelo. O embondeiro e a tolerância. Revista Eletrônica Direito e Política, Programa de Pós-Graduação Stricto Sensu em Ciência Jurídica da UNIVALI, Itajaí, v.16, n.1, $1^{0}$ quadrimestre de 2021. Disponível em: www.univali.br/direitoepolitica - ISSN 1980-7791.

a fronteira das diferenças que nos segregam à princípio. Impede a possibilidade de dar um fim aos problemas da diferença e entender que somos diferentes, mas iguais. Tiago era a possibilidade de entendimento; é o "menino branco que ultrapassou as fronteiras entre as culturas, apropriando-se dos conhecimentos africanos ancestrais". ${ }^{32}$

Em contraponto às ideias de tolerância e liberdade de expressão delineadas, diferentes autores apresentam diferentes formas de pensar a liberdade de expressão e o limite do tolerar os discursos. Considerarei as concepções de tolerância de Jeremy Waldron e Andrew Jason Cohen. Como se verá, enquanto o primeiro, no seu livro "The Harm in Hate Speech", defende limitações mais severas à liberdade de expressão com objetivo de resguardar a dignidade humana; o segundo, em seu livro "Toleration and Freedom From Harm", acredita que o estado só deve limitar a liberdade de expressão quando há dano, conferindo à tolerância uma maior extensão.

\section{A TOLERÂNCIA DO WALDRON SONHA PÁSSAROS?}

A análise a partir da ótica de Waldron é apropriada. Por um lado, Mia Couto trata em seu conto da dicotomia branco e negro, por outro, Waldron inicia seu livro questionando discurso de ódio contra um pai muçulmano e sua filha. Em ambos, questões de raça são o cerne.

Waldron, em seu livro "The Harm in Hate Speech", diz que a tolerância é relacionada aos laços de sociabilidade. Para ele, tolerância pressupõe tanto o direito das minorias de serem protegidas de ataques e sanções físicas em razão de sua crença e práticas religiosas (segurança), quanto o direito de serem bem tratados como membros da sociedade (pertencimento). Assim, a tolerância implicaria em tratar a minoria como "um membro comum da sociedade em boa condição, ao qual é atribuído as mesmas liberdades, proteções, e poderes que

32 MICHELETTI, Everton Fernando. O "terceiro espaço" em "O embondeiro que sonhava pássaros", de Mia Couto, e "A árvore que tinha batucada", de Boaventura Cardoso. p. 6-7. 
LACERDA TANURE, Augusto; CAMPOS GALUPPO, Marcelo. O embondeiro e a tolerância. Revista Eletrônica Direito e Política, Programa de Pós-Graduação Stricto Sensu em Ciência Jurídica da UNIVALI, Itajaí, v.16, n.1, $1^{0}$ quadrimestre de 2021. Disponível em: www.univali.br/direitoepolitica - ISSN 1980-7791.

todos os demais - e que gera demanda por reconhecimento e tratamento de acordo com sua condição digna" (tradução livre). ${ }^{33}$

A dignidade, para o autor, se traduziria em segurança e pertencimento. Assim, ele defende que tolerância é conceder o status social de pertencer à sociedade de forma respeitosa, como o é para alguém para quem a condição de ser minoria não é capaz de o desqualificar. ${ }^{34}$ Não defende, porém, a proteção ao simples desgostar de como o outro age, mas pretende restringir o discurso, no caso do discurso de ódio, para resguardar a minoria do dano que este poderia causar à segurança e ao pertencimento da minoria. ${ }^{35}$

Agora retornemos a dúvida que suspendemos anteriormente. é possível ordenar uma tolerância tão exigente? É possível demandar que os colonos adultos se abstenham de dizer o que pensam em nome de uma suposta paz? Waldron acredita que é possível e que esse é, essencialmente, o projeto iluminista:

Os trechos que mostrei para vocês de Bayle e Locke, Diderot e Voltaire, enfatizam como é incompleto um modelo de tolerância que somente restringe a coerção e a violência, deixando intocados o ódio, insultos e ostracismo. (...) No âmbito internacional, a analogia de um conceito de tolerância limitado à não perseguição e a proibição no uso da violência e coação para fins religiosos seria uma concepção de paz enquanto não guerra. Acho interessante que, de longe, teóricos iluministas não estavam satisfeitos com essa noção de paz. Eles queriam caminhar para uma harmonia entre nações mais afirmativa (tradução livre). ${ }^{36}$

Ao meu ver, o trecho contém um pequeno equívoco. Waldron invoca a imagem de que ao se instituir um modelo de tolerância que "somente restringe a coerção e a violência", a sociedade deixaria intocado o ódio, insultos e ostracismo. Entretanto, ao restringir a violência e a coação, a sociedade não os deixa intocados, permite o debate e debater não é o mesmo que deixar parado.

A discussão promove movimento no que se discute, no caso de Waldron e do conto de Mia Couto, o ódio. Se engana aquele que credita e acredita que o Direito é a

\footnotetext{
33 WALDRON, Jeremy. The Harm in Hate Speech. p. 219-220.

34 WALDRON, Jeremy. The Harm in Hate Speech. p. 105.

35 WALDRON, Jeremy. The Harm in Hate Speech. p. 138-139.

36 WALDRON, Jeremy. The Harm in Hate Speech. p. 220.
} 
LACERDA TANURE, Augusto; CAMPOS GALUPPO, Marcelo. O embondeiro e a tolerância. Revista Eletrônica Direito e Política, Programa de Pós-Graduação Stricto Sensu em Ciência Jurídica da UNIVALI, Itajaí, v.16, n.1, $1^{0}$ quadrimestre de 2021. Disponível em: www.univali.br/direitoepolitica - ISSN 1980-7791.

única forma de lidar com as questões da sociedade. Como indicado por Kant ${ }^{37}$, o direito sequer tem poder para verificar os motivos do agir. Sua força se encontra na capacidade de coação externa e não interna.

Por oportuno, imagine que no conto existisse um Direito afirmando a necessidade de se conferir ao passarinheiro "as mesmas liberdades, proteções, e poderes que todos os demais". Várias dúvidas nascem com este exercício. Nenhuma delas sobre a capacidade dos homens adultos continuarem com suas confabulações contra o passarinheiro dentro de suas casas e clubes. A pretensa equiparação não resolveria o ódio, criaria uma neblina impedindo que se atestasse a existência dele, afinal "no país x o racismo é proibido por lei", diriam os racistas. Instituiria uma verdadeira paz enquanto não guerra. A disposição legal obriga o tratar como parte da sociedade com os mesmos direitos e, por isso, impede o diálogo, na verdade, deixaria intocada a questão do ódio, ao confinar um dos lados (aquele que promove o ódio) para dentro das janelas.

O conto nos mostra a consequência de enclausurar o ódio dentro das casas. Em algum momento a bolha de ódio estoura e se transforma em uma onda de violência irrepreensível. Justificativas para a onda de violência são criadas, passarinheiros são presos e torturados, Tiagos são mortos.

Ao analisarmos o conto de Mia Couto, o único que parece alcançar a exigência de Waldron sobre tolerância enquanto pertencimento é Tiago. O menino era uma ponte entre a sociedade dos colonos adultos e o passarinheiro. Ao retornar de sua visita, entre as reprimendas do pai, encontrou espaço para contar sobre como o passarinheiro vivia e como era sábio. ${ }^{38}$ Paradoxalmente, Tiago é morto; a única ponte existente é rompida. Na violência, as pontes são rompidas. No diálogo se constrói pontes.

A questão, porém, se torna ainda mais complexa ao se constatar que nem Tiago tolerava. Tiago não se opõe ao passarinheiro. A existência de diferenças, por si só,

\footnotetext{
37 KANT, Immanuel. A Metafísica dos Costumes. Tradução de Jose Lamego. Lisboa: Fundação Calouste Bulbenkian, 2005. p.41-47.

38 COUTO, Mia.O Embondeiro que sonhava pássaros. p. 64-65.
} 
LACERDA TANURE, Augusto; CAMPOS GALUPPO, Marcelo. O embondeiro e a tolerância. Revista Eletrônica Direito e Política, Programa de Pós-Graduação Stricto Sensu em Ciência Jurídica da UNIVALI, Itajaí, v.16, n.1, $1^{0}$ quadrimestre de 2021. Disponível em: www.univali.br/direitoepolitica - ISSN 1980-7791.

não implica em tolerância. Como lembra Chassot, 39 o menino, não domesticado pela lógica racional colonizadora, percebe o passarinheiro como algo mágico, nobre. Assim, vê-se ainda mais difícil tal concepção de tolerância. Obriga-se aquele que se opõe a aceitar e, em alguma medida acolher, ao mesmo tempo que obriga o opositor a se abster de dizer o que pensa.

A exigência da tolerância de Waldron se torna ainda maior ao se constatar que o conceito dignidade, por si só, é um conceito complexo (não obstante a tentativa de restringir o conceito de dignidade para a conjugação de segurança e pertencimento traduzida em acolhida). Pode significar diferentes coisas para diferentes pessoas em diferentes contextos. Ao mesmo passo, seu conceito derivado: pertencimento. Pertencer tem origem no latim pertìnesc(e)re que significava: ser propriedade de (HOUAISS, 2009). Esse significado se manteve, mas também se relaciona, hoje, com ser parte de. Acredito, porém, que as pessoas busquem mais que ser propriedade de ou parte de algo, no caso da sociedade; elas querem ser acolhidas. Esse direito e vontade parecem legítimos, entretanto, não se confundem com tolerância. Tolerar não é acolher. Tolerar possui em si uma ideia de opor-se a algo, mas aceitar. Acolher, traz a ideia de "oferecer ou obter refúgio, proteção ou conforto físico; abrigar(-se), amparar(-se)"40, algo que se afasta da oposição inerente da tolerância. Exigir que todos acolham o que ou aquilo ao qual são opostos parece não ser a melhor das opções, parece não ser uma medida legal que traria frutos a não ser a reclusão da oposição por trás das janelas.

As ideias de Waldron, especialmente quando ele indica a necessidade de se censurar o discurso de ódio parecem ser questionáveis. Vejamos, então, sob o ponto de vista de Andrew Jason Cohen, será que suas ideias trariam melhor destino?

\footnotetext{
39 CHASSOT, Jaqueline. A lógica simbólica e a representação da personagem em "o embondeiro que sonhava pássaros", de mia couto. p. 30-31.

40 HOUAISS, Antônio. Houaiss Eletrônico
} 
LACERDA TANURE, Augusto; CAMPOS GALUPPO, Marcelo. O embondeiro e a tolerância. Revista Eletrônica Direito e Política, Programa de Pós-Graduação Stricto Sensu em Ciência Jurídica da UNIVALI, Itajaí, v.16, n.1, $1^{0}$ quadrimestre de 2021. Disponível em: www.univali.br/direitoepolitica - ISSN 1980-7791.

\section{A TOLERÂNCIA DO COHEN SONHA PÁSSAROS?}

Na perspectiva de Andrew Jason Cohen, em seu livro "Toleration and Freedom From Harm", tolerância é a possibilidade de: "um agente intencionalmente e por princípio se abster de interferir com um outro opositor (ou sua conduta, etc.), apesar de acreditar que possui poder para interferir" (tradução livre). ${ }^{41}$.

Tolerar, para Cohen, é agir e, portanto, ato de um agente, independentemente de como este se comportou no passado ou como tende a se comportar. Para ele importa o ato de tolerar em si; é o agir que pode ser tolerante ou não. Em sua análise, porém, não basta perceber as consequências do ato, o modo de agir deve ser intencionalmente e por princípio escolhido, razão pela qual é impossível tolerar um ato cuja existência se ignora ou ao qual se é indiferente. Para ser considerado tolerância, necessário que o agente acredite que seu ato é, de fato, a "coisa certa a fazer". 42

A tolerância é o abster de interferir, no qual interferir é "qualquer ato que tem o poder de impedir ou prevenir - mesmo que parcialmente - um agente de fazer como deseja ou pretende" (tradução livre). ${ }^{43}$ Entretanto, é um abster de interferir em algo ao qual se opõe, seja por razões morais, seja por simplesmente não gostar. ${ }^{44}$ Esse algo a ser tolerado, tal como exemplificado por Cohen, pode ser pessoas, crenças, comportamentos, práticas, dentre outras possibilidades. Não se trata só de como os outros agem. Pode ser que esse algo seja tão somente uma característica de difícil mudança, tal como a cor da pele, fundamento exclusivo da intolerância de alguns racistas. ${ }^{45}$ Por fim, tolerância pressupõe acreditar que se pode intervir. Para Cohen ${ }^{46}$ não é necessário que os racistas, por exemplo, possam de fato intervir, mas que acreditem possuir tal poder e, portanto, serão considerados tolerantes se acreditarem que possuem o poder de intervir, mas, por

\footnotetext{
${ }^{41}$ COHEN, Andrew Jason. Toleration And Freedom From Harm: liberalism reconceived. p. 68.

42 COHEN, Andrew Jason. Toleration And Freedom From Harm: liberalism reconceived. p. 54.

43 COHEN, Andrew Jason. Toleration And Freedom From Harm: liberalism reconceived. p. 61.

44 COHEN deixa claro que não são todas as ações às quais se opõe que justificam a utilização do conceito de tolerar. (COHEN, 2018, p. 63)

45 COHEN, Andrew Jason. Toleration And Freedom From Harm: liberalism reconceived. p. 65. 46 COHEN, Andrew Jason. Toleration And Freedom From Harm: liberalism reconceived. p. 67.
} 
LACERDA TANURE, Augusto; CAMPOS GALUPPO, Marcelo. O embondeiro e a tolerância. Revista Eletrônica Direito e Política, Programa de Pós-Graduação Stricto Sensu em Ciência Jurídica da UNIVALI, Itajaí, v.16, n.1, $1^{0}$ quadrimestre de 2021. Disponível em: www.univali.br/direitoepolitica - ISSN 1980-7791.

todos os motivos acima indicados, acreditando ser "a coisa certa a fazer", escolherem tolerar.

Em suma, é como se os colonos, identificando-se como possuidores do poder da coação, decidissem que apesar de poderem agir contra o passarinheiro, não o fariam, pois aquilo não seria correto. A concepção de tolerância de Andrew, portanto, é menos exigente que a de Waldron. Tolerar, para ele, não implica em pertencimento e acolhida, mas em oposição limitada por princípio (segurança). Limita-se, pela tolerância, a liberdade de interferir, na medida da necessidade de se garantir a todos o direito-dever de liberdade de dano. ${ }^{47}$

O único propósito que justifica o uso do poder sobre um agente, contra sua vontade, é prevenir aquele agente de causar dano à outros ou construir políticas de liberdade de dano mínimas, incluindo aquelas que envolvam taxas mínimas de impostos que possibilitem prevenir danos à outros, não interessando quem causaria o dano (tradução livre). ${ }^{48}$

Nesse sentido, para Cohen, a interferência (fim da tolerância) só é possível - não necessária, mas possível - quando analisada por meio do princípio de liberdade de dano, supra descrito. Quando o ato de alguém contraria a liberdade de dano, tal como quando os colonos se dirigem ao embondeiro para agredir o passarinheiro, a intervenção para impedir que os colonos atacassem o passarinheiro, desde que se respeite a proporcionalidade, é legítima, pois atua sobre um interesse injusto. ${ }^{49}$ Portanto, para o autor, o agir tolerante deve ser a abstenção de interferir obrigando/impedindo determinada conduta (coerção), limitando-se no direitodever de liberdade de dano. Assim, uma conversa que pretende persuadir não é interferência, na medida em que não obriga/impede, pois alguém poderia ouvir as considerações e simplesmente desconsiderá-las.

A dificuldade na teoria de Cohen, no entanto, passa a ser estabelecer o que é um ato/interesse injusto. Segundo o autor, a liberdade deve ser a máxima possível, tal qual sua tolerância. Portanto, a liberdade só pode sofrer interferências em casos específicos, quais sejam, quando limitada pelo princípio da liberdade de dano

\footnotetext{
47 COHEN, Andrew Jason. Toleration And Freedom From Harm: liberalism reconceived. p. 150.

${ }^{48} \mathrm{COHEN}$, Andrew Jason. Toleration And Freedom From Harm: liberalism reconceived. p. 155.

${ }^{49} \mathrm{COHEN}$, Andrew Jason. Toleration And Freedom From Harm: liberalism reconceived. p. 170173.
} 
LACERDA TANURE, Augusto; CAMPOS GALUPPO, Marcelo. O embondeiro e a tolerância. Revista Eletrônica Direito e Política, Programa de Pós-Graduação Stricto Sensu em Ciência Jurídica da UNIVALI, Itajaí, v.16, n.1, $1^{0}$ quadrimestre de 2021. Disponível em: www.univali.br/direitoepolitica - ISSN 1980-7791.

edificado na justiça do ato praticado. No entanto, depender do conceito de justo e injusto (wrongfully) pode complicar a análise de uma liberdade e uma tolerância que se pretendem máximas. Ora, o conceito de justiça presente nas ideias sobre o limite de tolerância de Cohen nos traz a seguinte questão: justo para quem? Nos deparamos com a mesma dificuldade que a dignidade de Waldron nos trouxe: uma multiplicidade de significados que acaba minando o limite da tolerância que deveria ser estrito ao se tentar estabelecer um patamar comum mínimo de liberdade. Assim, aqueles que determinam o que é o justo em determinada sociedade, criam a coexistência de múltiplos mínimos de liberdade.

A tolerância de Cohen, diferentemente da idealizada por Waldron, tem como propósito estabelecer um patamar mínimo de liberdade. Acredito que ela não consiga alcançar o propósito ao qual se propõe, entretanto, desconsideremos este fato. Não importa muito se ela é capaz ou não de acabar, por si só, com o ódio, mas o fato de que ao tentar estabelecer o máximo de liberdade possível, ela possibilita diálogo e, portanto, garante movimento e questionamento, restringindo a possibilidade de violência pelo princípio da liberdade de dano. A dúvida, agora, se transforma em outra: qual o valor de se afirmar uma tolerância que não pressupõe acolhimento e pertencimento, tal como faz a teoria de Cohen?

\section{A TOLERÂNCIA QUE SONHA PÁSSAROS}

Por um lado, a tolerância de Waldron é muito exigente e não impede que o ódio se dissemine, por outro a de Cohen traz um mínimo de medidas para que um lado não se imponha sob o outro de forma violenta. Considerando que preferiríamos acabar com o ódio, nenhuma das duas é suficiente. Então, por que deveríamos nos ater ao mínimo, como pensado também por Cohen? Por que não deveríamos determinar quais assuntos deveriam ser tratados e quais deveriam ser combatidos, tal como Waldron ${ }^{50}$ acredita ser o certo a ser feito? Em suma, por que não poderíamos determinar previamente que o discurso de ódio, por exemplo, não pertence às ideias que formariam essa sociedade que sonha pássaros?

\footnotetext{
50 WALDRON, Jeremy. The Harm in Hate Speech. p. 33.
} 
LACERDA TANURE, Augusto; CAMPOS GALUPPO, Marcelo. O embondeiro e a tolerância. Revista Eletrônica Direito e Política, Programa de Pós-Graduação Stricto Sensu em Ciência Jurídica da UNIVALI, Itajaí, v.16, n.1, $1^{0}$ quadrimestre de 2021. Disponível em: www.univali.br/direitoepolitica - ISSN 1980-7791.

Para John Stuart Mill51, a razão se encontra na necessidade de se proteger, sempre, a possibilidade do debate. Para o autor, o progresso natural da humanidade acaba consolidando algumas opiniões, entretanto, é necessário manter aberto o mercado de ideias, razão pela qual é necessário fomentar o debate. ${ }^{52}$ Aplicando sua ideia no problema posto, a liberdade de expressão deve ser protegida, ao passo que, ainda que tivéssemos uma ideia consolidada 1) sobre o que é o discurso de ódio, 2) sobre a necessidade de o combater e 3) sobre como deveríamos combatê-lo, nossas certezas não passariam de meias verdades e, portanto, seria mais prudente possibilitar, sempre, a revisão de tais verdades facultando sua eterna construção e, assim, conservar a liberdade de expressão.

Outra resposta à questão "por que deveríamos nos ater ao mínimo?" se encontra nos estudos de Baker. Em suma, para o autor, a necessidade de se pensar a tolerância mais extensa possível e, portanto, com menores limitações à liberdade de expressão, se encontra na impossibilidade de limitar as liberdades individuais. Para ele, o discurso é importante para saber, por exemplo, o que as pessoas acham sobre determinado ponto na sociedade, suas visões de mundo e sua própria revelação para o mundo. ${ }^{53}$ Nesse caso, cabe destacar que o discurso de ódio deveria ser possível na medida em que as pessoas deveriam poder dizer o que pensam e expressar quem são, sob pena de se construir, aos poucos, o contexto para que a violência súbita surja, tal como as conversas por trás das janelas geraram no conto.

Há, ainda, o ponto de vista de Dworkin, provavelmente o argumento mais significativo no que tange a necessidade de proteção da liberdade de expressão, para quem só há legitimidade na coação estatal quando todos puderam contribuir

\footnotetext{
51 Não é o objetivo do artigo indicar os detalhes das concepções de liberdade e tolerância dos autores citados, empreitada impossível para um artigo tão curto. A idéia deste capítulo é, tão somente, possibilitar uma breve diferenciação dos motivos pelos quais outros autores defendem a necessidade de se limitar o mínimo possível a liberdade (e da liberdade de expressão) das pessoas. Faz-se isso para que seja mais fácil perceber a idéia deste artigo: a liberdade de expressão como elemento chave para combater o ódio.

52 MEDRADO, Vitor. Liberdade de expressão e democracia no brasil: a consolidação da jurisprudência brasileira em diálogo com o constitucionalismo norte-americano. Belo Horizonte: Dialética, 2019. p. 33-34.

53 MEDRADO, Vitor. Liberdade de expressão e democracia no brasil: a consolidação da jurisprudência brasileira em diálogo com o constitucionalismo norte-americano. p. 119.
} 
LACERDA TANURE, Augusto; CAMPOS GALUPPO, Marcelo. O embondeiro e a tolerância. Revista Eletrônica Direito e Política, Programa de Pós-Graduação Stricto Sensu em Ciência Jurídica da UNIVALI, Itajaí, v.16, n.1, $1^{0}$ quadrimestre de 2021. Disponível em: www.univali.br/direitoepolitica - ISSN 1980-7791.

para o ambiente moral do qual são parte. A ideia da necessidade de liberdade de expressão, nesse caso, tem como base a própria legitimidade da coerção. Assim, "uma democracia justa requer não só o voto, mas a voz" (tradução livre). ${ }^{54}$

Merece destaque a ineficiência de se restringir a liberdade de expressão quando do combate do discurso de ódio, tal como pontuada por Matheus Assaf. 55 O autor coleciona em seu livro diversos exemplos nacionais e internacionais de censuras a discursos de ódio que acabam impulsionando os próprios discursos de ódio e aqueles que os proferem. Novamente, coibir o discurso de ódio restringindo a liberdade de expressão provoca efeitos contrários aos pretendidos: ora escondese o ódio, levando-o para dentro das casas, ora confere a ele projeção.

Além disso, como lembrado por Assaf ${ }^{56}$ há sempre um problema quanto aos critérios que decidem o que deve ser banido da salvaguarda da liberdade de expressão. São sempre discricionários. Nesse caso, a discricionariedade de alguns (ainda que alguns representem a maioria) sobre o que deve ser e o que não deve ser dialogado, é demasiadamente perigosa. A voz do dissonante deve ser preservada.

Tais razões são de importância ímpar. Entretanto, não são elas que nos fazem imaginar uma tolerância que sonhe pássaros. Há algo diferente que a literatura de Mia Couto deixa escapar por suas entrelinhas: as relações humanas.

O que é capaz de transformar ódio, no conto, parece ser estabelecer conexão humana, preocupar-se com o outro, acolhê-lo. Mas, antes de acolher, é necessário diálogo (não monólogo) e, portanto, um patamar mínimo de tolerância. Afinal, por um lado, não é possível exigir acolhida sob pena de nunca ser acolhedora, por outro lado, não é possível existir acolhida sob o manto do não dizer. Se não se pode expressar, há sempre o risco de a acolhida se tornar violência e a paz, de

\footnotetext{
${ }^{54}$ DWORKIN, Ronald. A new map of censorship. In: Index of Censorship. Londres, 1994. p. 13. 55 ASSAF, Matheus. Liberdade de expressão e discurso de ódio: por que devemos tolerar ideias odiosas?. Belo Horizonte: Dialética, 2019. p. 269-291.

${ }^{56}$ ASSAF, Matheus. Liberdade de expressão e discurso de ódio: por que devemos tolerar ideias odiosas?.p. 273-282; 297-298.
} 
LACERDA TANURE, Augusto; CAMPOS GALUPPO, Marcelo. O embondeiro e a tolerância. Revista Eletrônica Direito e Política, Programa de Pós-Graduação Stricto Sensu em Ciência Jurídica da UNIVALI, Itajaí, v.16, n.1, $1^{0}$ quadrimestre de 2021. Disponível em: www.univali.br/direitoepolitica - ISSN 1980-7791.

fato, nunca ser construída. Não é possível relacionar-se de forma saudável sob a iminência permanente e velada de violência.

Pelo contrário, é justamente a liberdade de expressão que permite a mudança na sociedade dos colonos. O passarinheiro, mesmo sendo sombra, traz música para a cidade. Seus pássaros outrora presos, invadem as casas. A gaita ecoa cantos e seus encantos reverberam, incomodam. A liberdade de expressão faz mudar. É verdade, alguns se posicionam contra a presença do passarinheiro - tal como os colonos adultos, mas outros à favor - tal como Tiago. O que antes era o outro, passa a ser para alguns uma relação, passa a ser "uma pessoa de grande valor". Se no começo as crianças eram ensinadas a não tolerar, se antes eram ensinadas a criarem preconceitos, com a liberdade de expressão presente na música do passarinheiro, elas passam a desafiar a ordem, passam a questionar. Não é que a liberdade de expressão seja a solução para todos os problemas, é que ela traz a possibilidade de solução.

Os críticos à liberdade de expressão, no caso do discurso de ódio, preferem perceber as pessoas que veem o discurso de ódio e, após, concordam e acreditam nele. Enxergam somente que o discurso de ódio alimenta o ódio. Esquecem que, assim como literatura, existem aqueles que leem a situação e identificam ser esdrúxula. Que percebem a necessidade de lutar contra ele. Exemplo disso é a recente repercussão do discurso do secretário da cultura Ricardo Alvim. ${ }^{57}$

Não afirmo que não existirão pessoas que tenderão a propagar o ódio, mas prefiro dar a elas a chance de mudarem, do que condená-las a odiar por toda a vida. Enquanto o ódio for confinado às casas e clubes, resistirá na irrefutabilidade do monólogo. Prefiro acreditar que as pessoas, como no caso recente brasileiro, terão discernimento de que odiar é errado e repudiarão o ato. A liberdade de expressão cria um espaço de dúvida, essencial à luta contra o ódio; imprescindível para que as pessoas questionem os valores que as fazem sustentar posicionamentos

57 BRITO, Ricardo; PARAGUASSU, Lisandra. Bolsonaro demite Alvim da Secretaria da Cultura após polêmica sobre ministro nazista. Thomson Reuters. Disponível em: <https://br.reuters.com/article/topNews/idBRKBN1ZG20G-OBRTP>. Acesso em: 28/02/2020. 
LACERDA TANURE, Augusto; CAMPOS GALUPPO, Marcelo. O embondeiro e a tolerância. Revista Eletrônica Direito e Política, Programa de Pós-Graduação Stricto Sensu em Ciência Jurídica da UNIVALI, Itajaí, v.16, n.1, $1^{0}$ quadrimestre de 2021. Disponível em: www.univali.br/direitoepolitica - ISSN 1980-7791.

preconceituosos, tarefa muito difícil de ser realizada exclusivamente pela coação externa da lei.

\section{CONSIDERAÇÕES FINAIS}

A tolerância que sonha pássaros é aquela que permite o diálogo. É aquela acredita nas relações humanas, utilizando da lei e da coação externa somente para impedir que a violência massacre os diferentes discursos e sonhos, ou seja, para impedir que um dos lados opositores, no caso do conto: colonos adultos e passarinheiro, usem da violência para reafirmar suas convicções e protegê-las de eventuais críticas mediante a supremacia do poder que possuem de impor determinada coação legal. A tolerância que sonha pássaros é aquela que visa construir uma paz um pouco mais consistente e não fundada nas sombras do ódio; no engano do silencio; na potência de violência.

\section{REFERÊNCIAS DAS FONTES CITADAS}

ASSAF, Matheus. Liberdade de expressão e discurso de ódio: por que devemos tolerar ideias odiosas?. Belo Horizonte: Dialética, 2019.

BETTO, Frei. Arte da Tolerância. Disponível em: https://www.freibetto.org/index.php/artigos/14-artigos/18-arte-da-tolerancia. Acesso em: 15/11/2019

BEZERRA, Rosilda Alves; TEIXEIRA, João Batista. Relações identitárias e infância no conto de mia couto: o embondeiro que sonhava pássaros. In. $V$ Colóquio Internacional Cidadania Cultural: Jovens nos espaços públicos e institutucionais da modernidade, 2011.

BRAGA, Giampaolo Morgado. Em segurança pública, nosso problema é excesso de tolerância. Revista Época, Rio de Janeiro. Disponível em: <https://epoca.globo.com/em-seguranca-publica-nosso-problema-excesso-detolerancia-23634880>. Acesso em: 15/11/2019

BRITO, Ricardo; PARAGUASSU, Lisandra. Bolsonaro demite Alvim da Secretaria da Cultura após polêmica sobre ministro nazista. Thomson Reuters. Disponível em: <https://br.reuters.com/article/topNews/idBRKBN1ZG20G-OBRTP>. Acesso em: 28/02/2020. 
LACERDA TANURE, Augusto; CAMPOS GALUPPO, Marcelo. O embondeiro e a tolerância. Revista Eletrônica Direito e Política, Programa de Pós-Graduação Stricto Sensu em Ciência Jurídica da UNIVALI, Itajaí, v.16, n.1, $1^{0}$ quadrimestre de 2021. Disponível em: www.univali.br/direitoepolitica - ISSN 1980-7791.

BUGALHO, Henry. Eles não podem vencer: a intolerância não pode sufocar a voz dos tolerantes. Carta Capital, Rio de Janeiro. Disponível em: https://www.cartacapital.com.br/opiniao/eles-nao-podem-vencer-a-intolerancianao-pode-sufocar-a-voz-dos-tolerantes/. Acesso em: 15/11/2019

CHASSOT, Jaqueline. A lógica simbólica e a representação da personagem em "o embondeiro que sonhava pássaros", de mia couto. Revista InterteXto, v. 3, n. 2, jan. 2011. Disponível em: <http://seer.uftm.edu.br/revistaeletronica/index.php/intertexto/article/view/108 >. Acesso em: 11 jan. 2020.

COUTO, Mia.O Embondeiro que sonhava pássaros.In: .Cada homem é uma raça. São Paulo: Companhia das Letras, 2013.

COHEN, Andrew Jason. Toleration And Freedom From Harm: liberalism reconceived. New York: Routledge, 2018.

DWORKIN, Ronald. A new map of censorship. In: Index of Censorship. Londres, 1994

HOUAISS, Antônio. Houaiss Eletrônico. Rio de. Janeiro, Ed. Objetiva, 2009

MICHELETTI, Everton Fernando. O "terceiro espaço" em "O embondeiro que sonhava pássaros", de Mia Couto, e "A árvore que tinha batucada", de Boaventura Cardoso. Campina Grande: Editora Realize. 2013. XIII Congresso Internacional da ABRALIC Internacionalização do Regional. Disponível em: <https://www.editorarealize.com.br/revistas/abralicinternacional/trabalhos/Com pleto_Comunicacao_oral_idinscrito_687_03bc553d89a018eae05335d7074beaa8. pdf $>$. Acesso em: 11/01/2020.

MICELI Maria Zélia Dias. A intolerância no brasil e no mundo. Estadão, São Paulo. Disponível em: https://educacao.estadao.com.br/blogs/blog-dos-colegios-santaamalia/a-intolerancia-no-brasil-e-no-mundo/ Acesso em 15/11/2019.

MEDRADO, Vitor. Liberdade de expressão e democracia no brasil: a consolidação da jurisprudência brasileira em diálogo com o constitucionalismo norte-americano. Belo Horizonte: Dialética, 2019.

KANT, Immanuel. A Metafísica dos Costumes. Tradução de Jose Lamego. Lisboa: Fundação Calouste Bulbenkian, 2005.

WALDRON, Jeremy. The Harm in Hate Speech. Cambridge: Harvard University Press, 2012.

RECEBIDO EM: FEV/2020

APROVADO EM: AGO/2020 